OPEN ACCESS

Edited by: John R. Battista, Louisiana State University,

United States

Reviewed by:

Heriberto Fernandez,

Austral University of Chile, Chile

Zuowei Wu,

lowa State University, United States

*Correspondence: Maarten J. Gillbert

m.j.gillbert@uu.n

Specialty section:

This article was submitted to Evolutionary and Genomic

Microbiology,

a section of the journal

Frontiers in Microbiology

Received: 24 January 2019

Accepted: 30 April 2019

Published: 15 May 2019

Citation:

Gilbert MJ, Duim B, Zomer AL and Wagenaar JA (2019) Living

in Cold Blood: Arcobacter,

Campylobacter, and Helicobacter

in Reptiles. Front. Microbiol. 10:1086.

doi: 10.3389/fmich.2019.01086

\section{Living in Cold Blood: Arcobacter, Campylobacter, and Helicobacter in Reptiles}

\author{
Maarten J. Gilbert ${ }^{1,2 *}$, Birgitta Duim ${ }^{1,3}$, Aldert L. Zomer ${ }^{1,3}$ and Jaap A. Wagenaar ${ }^{1,3,4}$ \\ ${ }^{1}$ Department of Infectious Diseases and Immunology, Faculty of Veterinary Medicine, Utrecht University, Utrecht, \\ Netherlands, ${ }^{2}$ Reptile, Amphibian and Fish Conservation Netherlands, Nijmegen, Netherlands, ${ }^{3}$ WHO Collaborating Center \\ for Campylobacter/OIE Reference Laboratory for Campylobacteriosis, Utrecht, Netherlands, ${ }^{4}$ Wageningen Bioveterinary \\ Research, Lelystad, Netherlands
}

Species of the Epsilonproteobacteria genera Arcobacter, Campylobacter, and Helicobacter are commonly associated with vertebrate hosts and some are considered significant pathogens. Vertebrate-associated Epsilonproteobacteria are often considered to be largely confined to endothermic mammals and birds. Recent studies have shown that ectothermic reptiles display a distinct and largely unique Epsilonproteobacteria community, including taxa which can cause disease in humans. Several Arcobacter taxa are widespread amongst reptiles and often show a broad host range. Reptiles carry a large diversity of unique and novel Helicobacter taxa, which apparently evolved in an ectothermic host. Some species, such as Campylobacter fetus, display a distinct intraspecies host dichotomy, with genetically divergent lineages occurring either in mammals or reptiles. These taxa can provide valuable insights in host adaptation and co-evolution between symbiont and host. Here, we present an overview of the biodiversity, ecology, epidemiology, and evolution of reptile-associated Epsilonproteobacteria from a broader vertebrate host perspective.

Keywords: Arcobacter, Campylobacter, Helicobacter, Epsilonproteobacteria, reptile, biodiversity, ecology, evolution

\section{INTRODUCTION}

With the advent of next generation sequencing techniques, recent years have seen growing research possibilities in bacterial biodiversity, ecology, epidemiology, and evolution. Especially the interplay between the microbiota and the vertebrate host has received much attention. Although vertebrate-associated Epsilonproteobacteria, primarily comprising taxa of the genera Arcobacter, Campylobacter, and Helicobacter, usually form a relatively small part of the vertebrate microbiota based on species abundance, they include some significant pathogens, such as Campylobacter jejuni and Helicobacter pylori. However, many of those species may be pathogenic in a particular host, while having a commensal or even mutualistic relationship with other hosts (Hermans et al., 2012; Lin and Koskella, 2015). Due to a varying degree of host association and adaptation, both generalists and specialists can be recognized.

Much focus has been on the microbiota of avian and mammalian hosts, while reptiles, which form a physiologically distinct, yet evolutionary intermediate group of amniotic vertebrates between mammals and birds, are relatively understudied. Although diverse and paraphyletic 
when omitting the related birds, reptiles are often grouped together based on shared features, such as a dependency on external heath sources (ectothermy). Compared to endothermic birds and mammals, ectothermic reptiles show a distinct physiology. Reptiles often show considerable fluctuations and a lower average body temperature compared to most endothermic vertebrates. Although ectothermic, reptiles are phylogenetically closely related to birds. As such, Epsilonproteobacteria species composition in reptiles could be either determined by physiology or phylogeny. Characteristics shared by nearly all reptiles, such as an ectothermic lifestyle, could select for a microbiota distinct from the microbiota encountered in endothermic vertebrates and might obscure phylogenic ancestry. Due to the distinct phylogeny and physiology compared to birds and mammals, reptiles can provide valuable insights in Epsilonproteobacteria host adaptation and co-evolution.

Not much is known about the biodiversity, ecology, epidemiology, and evolution of reptile-associated Epsilonproteobacteria. These aspects will be explored in this review from a broader vertebrate host perspective.

\section{EPSILONPROTEOBACTERIA DIVERSITY AND TAXONOMY}

The epsilon subclass of the Proteobacteria (Epsilonproteobacteria) comprises high species diversity. Members of the Epsilonproteobacteria have been found in a wide range of niches, varying from deep-sea vents to plant roots and the vertebrate gastrointestinal tract. Most vertebrate-associated species belong to the genera Arcobacter, Campylobacter, Helicobacter, and Wolinella (Figure 1). In contrast to Arcobacter, of which several members are free-living in the environment or associated with non-vertebrate hosts, Campylobacter and Helicobacter are predominantly associated with vertebrate hosts. All these genera consist of Gram-negative, often spiral or curved rod-shaped and flagellated, motile bacteria. Most members grow optimally at reduced oxygen levels (microaerobic atmosphere), although some members grow anaerobically, and especially members of the Arcobacter genus can grow aerobically. All currently known vertebrate-associated species are primarily associated with the digestive tract or the reproductive tract. Most members are considered commensals, but pathogenicity in humans and other animals varies per species or strain. Important pathogens in humans include Campylobacter jejuni, which is a leading cause of gastroenteritis in many countries (Olson et al., 2008), and Helicobacter pylori, the bacterial agent associated with gastric ulcers and gastric cancer (Parsonnet et al., 1991). A noteworthy pathogen in animals is Campylobacter fetus, which can cause fertility problems and abortion, predominantly in ruminants, but can also cause occasional infection in humans, often with a systemic component in people with underlying illness (Blaser et al., 2008; Wagenaar et al., 2014). Besides these species, many other species have been associated with disease as well (Solnick and Schauer, 2001; Debruyne et al., 2008; Collado and Figueras, 2011).
The number of validly described Campylobacter, Arcobacter, and Helicobacter species has increased steadily. Campylobacter fetus, initially described as Vibrio fetus, was the first Epsilonproteobacteria species described (Smith and Taylor, 1919). With the discovery of novel species and introduction of sequencebased methods several highly divergent clades emerged, which demanded a thorough revision of Campylobacter taxonomy. Campylobacter was split in two families: the Campylobacteraceae, comprising the genera Arcobacter, Campylobacter, and Sulfurospirillum, and in the Helicobacteraceae, comprising the genera Helicobacter and Wolinella (Goodwin et al., 1989; Vandamme et al., 1991). Based on recent genomic analyses it was found that the Epsilonproteobacteria were not monophyletic with all other classes of Proteobacteria, and reassignment of this group to the novel phylum Campylobacterota has been proposed (Waite et al., 2017). Additionally, the genera Arcobacter and Sulfurospirillum were removed from the family Campylobacteraceae and reassigned to the novel families Arcobacteraceae and Sulfurospirillaceae, respectively, and Helicobacter and Wolinella are the only genera in the family Helicobacteraceae. In addition, the genera Campylobacter and Helicobacter consist of several distinct clades which may represent separate genera. Pending more research in support of these reassignments, the current taxonomy will be used here. In total, 24 Arcobacter species, 31 Campylobacter species, and 41 Helicobacter species have been validly described at the moment of writing ${ }^{1}$.

\section{EPSILONPROTEOBACTERIA ECOLOGY}

In general, vertebrate-associated Arcobacter and, to a lesser extent, Campylobacter species show a broad host association, whereas most Helicobacter species show a more confined host association. These differential host dependencies are reflected in the genome sizes of these different genera, with a certain degree of genomic reduction observed in the vertebrate host-adapted Campylobacter and Helicobacter, which is less pronounced in Arcobacter. Arcobacter genomes encode a more diverse array of pathways than Campylobacter and Helicobacter, which often show incomplete pathways or lack certain pathways completely.

The ecology and host association of Arcobacter, Campylobacter, and Helicobacter can partly be explained by their physical properties. None of these genera are forming endospores and all are depending on moist conditions, making them susceptible to desiccation.

The genus Arcobacter comprises free-living species and animal- and plant-associated species. The habitat of Arcobacter members is highly diverse. Species have been isolated from sewage, estuarine sediments, marine and hyper saline environments, plant roots, and animals, including bivalve mollusks (Collado and Figueras, 2011). This habitat can be explained by certain characteristics shared by most species. Most members of the genus Arcobacter are able to grow at atmospheric oxygen levels. Many show an

\footnotetext{
${ }^{1}$ www.bacterio.net/index.html
} 


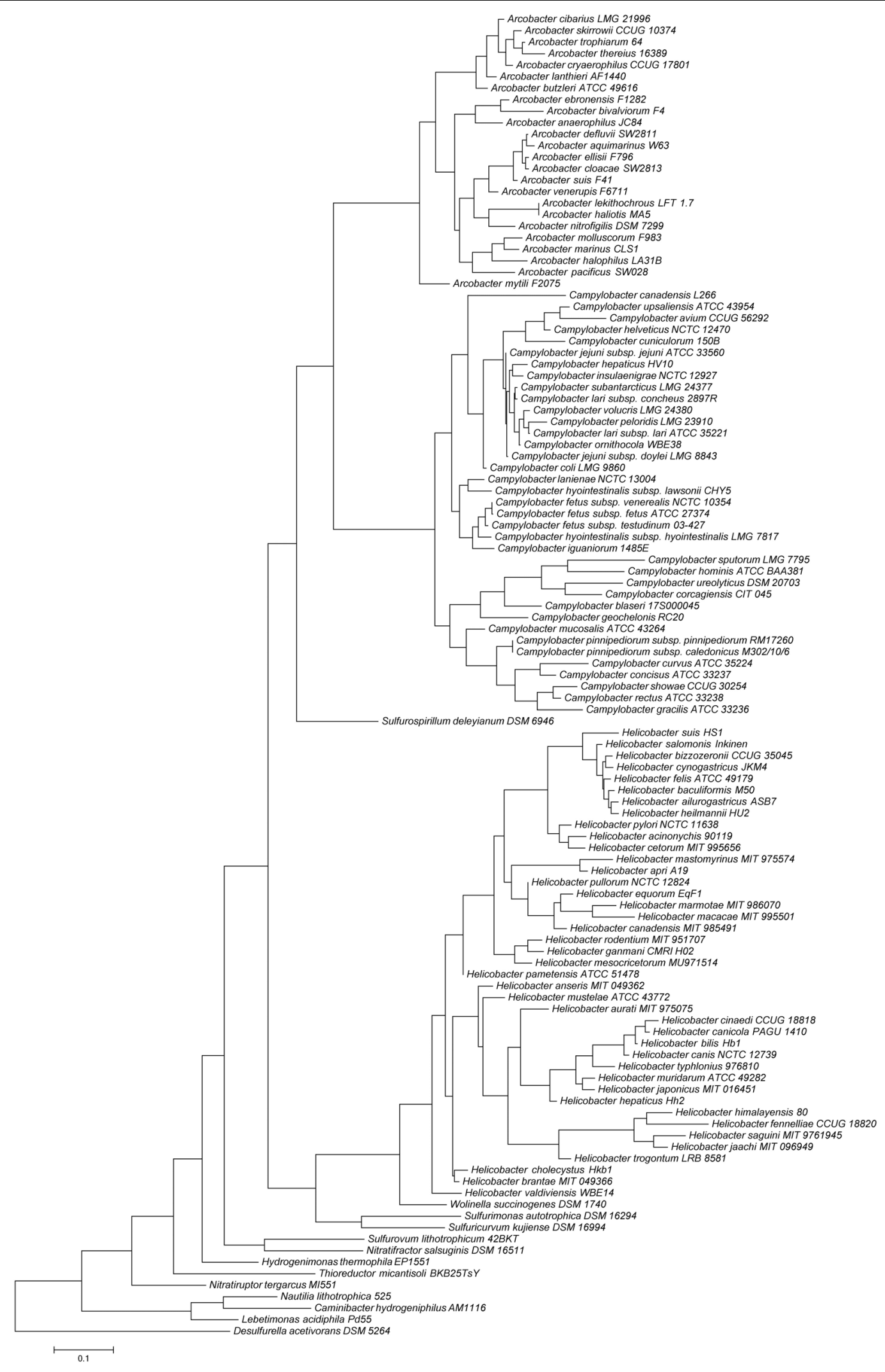

FIGURE 1 | Epsilonproteobacteria 16S rRNA gene phylogeny, including all Arcobacter, Campylobacter, and Helicobacter species and the type species of the remaining genera. Desulfurella acetivorans was used as outgroup and root of the tree. 
optimum growth at lower temperatures than Campylobacter and Helicobacter $\left(18-37^{\circ} \mathrm{C}\right)$, and show no or less optimal growth at higher temperatures $\left(37-42^{\circ} \mathrm{C}\right)$ (On et al., 1996). Relatively few Arcobacter species are associated with vertebrate hosts.

All Campylobacter species are associated with vertebrate hosts and many species show a broad host range. Members of this genus have been isolated from the vertebrate digestive tract and reproductive organs. Intestinal Campylobacter species show a strong affinity to the intestinal mucosa. As such, members of the Campylobacter genus show no or little growth at atmospheric oxygen levels; most prefer a microaerobic atmosphere and some grow at anaerobic conditions. This genus shows a wide growth temperature range, from 18 to $42^{\circ} \mathrm{C}$, but most members show growth at $30-37^{\circ} \mathrm{C}$ (On et al., 1996). Due to its implication in human disease, most research has focused on C. jejuni.

All Helicobacter species are associated with vertebrate hosts and often show high host specificity. Helicobacter species are not or rarely isolated from environmental sources. Within the genus Helicobacter urease producing gastric species and enterohepatic species are recognized. Helicobacter species are commonly present as a part of the vertebrate gastric, enteric, and hepatobiliary biota (Solnick and Schauer, 2001). All members of the Helicobacter genus show no or little growth at atmospheric oxygen levels; most prefer a microaerobic or anaerobic atmosphere. Most species show optimal growth at $37-42^{\circ} \mathrm{C}$ (On et al., 1996). As a human pathogen, most research has focused on the gastric species $H$. pylori, which shows an intricate relationship with its human host (Atherton and Blaser, 2009).

\section{THE REPTILIAN HOST}

Within the extant amniotic vertebrates, reptiles comprise a diverse class of animals, which are grouped together based on several internal and external characteristics shared by all or most members. In general, whereas mammals and birds are endothermic and have more constant body temperatures (homeothermic), reptiles are ectothermic and largely dependent on external heat sources for their preferred body temperatures, which can show considerable fluctuations (poikilothermic). Within the extant reptiles three major lineages can be discerned: Crocodilia (crocodiles); Lepidosauria, which consists of Sphenodontia (tuatara) and Squamata (lizards and snakes); and Testudines (chelonians). However, based on phylogeny, extant reptiles are considered paraphyletic as birds are excluded from reptilian phylogeny; the most recent common ancestor of all extant reptiles is the ancestor of all birds as well. In this respect, crocodilians are an interesting group to analyze the Epsilonproteobacteria species composition and co-evolution, since they are phylogenetically closer related to birds than to other ectothermic reptiles, but in contrast to endothermic birds display an ectothermic lifestyle. However, the Epsilonproteobacteria composition of crocodilians is poorly known.

Most of the extant reptiles are carnivorous, especially snakes and crocodiles, although the diet is supplemented by a certain amount of plant matter in many lizards and chelonians, and some species, especially tortoises, are considered herbivorous. As has been shown for other vertebrates (Ley et al., 2008), the diet and associated physiology of the gastrointestinal tract might be important factors in determining the intestinal microbiota composition.

Also, the host defense system might also play an important role in the microbiota composition. The reptilian immune system is distinct from the avian and mammalian immune system on several aspects. In contrast to birds and mammals, reptiles do not form germinal centers and lack Peyer's patches, aggregations of lymphoid tissue which sample antigen directly from the lumen of the intestinal tract and are usually found in the lowest part of the small intestine (Zimmerman et al., 2010). Little is known about the adaptive immune response of reptiles. However, the innate immune system, including components such as non-specific leukocytes, antimicrobial peptides, the complement system, and toll-like receptors, responds quickly as a non-specific first line of defense against a broad range of pathogens and in many cases the responses are stronger than those of mammals (Zimmerman et al., 2010), although this may vary depending on the pathogen (Voogdt et al., 2016).

\section{THE REPTILIAN BACTERIAL MICROBIOTA}

Relatively little is known about the reptilian intestinal microbiota. Amongst others, the intestinal microbiomes of the Galápagos land iguana (Conolophus subcristatus), Galápagos marine iguana (Amblyrhynchus cristatus), Liolaemus species, Phymaturus williamsi, Anolis species, the Burmese python (Python bivittatus), American alligator (Alligator mississippiensis), and the green turtle (Chelonia mydas) have been determined by sequence-based methods (Costello et al., 2010; Hong et al., 2011; Keenan et al., 2013; Ren et al., 2016; Kohl et al., 2017; Ahasan et al., 2018). Some of these studies showed that the microbiota changed drastically upon food intake after periods of fasting (Costello et al., 2010; Keenan et al., 2013). At the phylum level, Firmicutes and Bacteroidetes dominated the fecal microbiota of most species, but Fusobacteria dominated in American alligators, which is unique amongst mammals and reptiles, and which might reflect their archosaur ancestry (Keenan et al., 2013). However, in green turtles (Chelonia mydas) Proteobacteria were dominating and Campylobacter fetus was significantly abundant (Ahasan et al., 2018). A bacterial phylum-level analysis of fecal microbiome data showed that microbiome compositions did not reflect host phylogenetic affiliations or diet for reptiles (Keenan et al., 2013), although a significant correlation between diversity of the intestinal bacterial microbiota and phylogeny was observed in related Anolis species, suggesting that the radiation of this host lineage has influenced the diversification of their microbiota (Ren et al., 2016). In mammals it has been shown that host diet and phylogeny both influence bacterial diversity, which increases from carnivory to omnivory to herbivory, and that bacterial communities co-diversified with their hosts, which could be explained by 
effective vertical transmission in mammals (Ley et al., 2008; Ochman et al., 2010). As in mammals, a more diverse intestinal microbiota is expected as well in hindgut fermenting omnivorous and herbivorous reptiles.

\section{REPTILES AS A NEWLY DETECTED HOST FOR EPSILONPROTEOBACTERIA}

The Epsilonproteobacteria genera Campylobacter, Arcobacter, and Helicobacter are frequently isolated from various vertebrate hosts, primarily mammals and birds. The description of C. fetus from a chelonian during the eighties of the last century was the first Epsilonproteobacteria species reported from reptiles (Harvey and Greenwood, 1985). After that initial finding more Arcobacter, Campylobacter, and Helicobacter species have been reported to be isolated from reptiles. Arcobacter butzleri and a Helicobacter species have been isolated from tortoises (Debruyne et al., 2008; Stacy and Wellehan, 2010). A genetically distinct variant of Campylobacter fetus was isolated from reptiles and from humans that had direct or indirect contact with reptiles (Harvey and Greenwood, 1985; Tu et al., 2004; Dingle et al., 2010; Wang et al., 2013). This reptile-associated C. fetus has been shown to cause infection in humans with underlying disease (Tu et al., 2004). Another Campylobacter fetus-like species was isolated from the feces of a sick leopard tortoise (Stigmochelys pardalis) (Benejat et al., 2014). Following these case reports, it was shown that reptiles comprise a significant reservoir for Arcobacter, Campylobacter, Helicobacter, and Sulfurospirillum species, including potential novel species (Gilbert et al., 2014). The predominating Campylobacter taxa in reptiles, C. fetus subsp. testudinum and C. iguaniorum, have been described as a novel subspecies and species, respectively (Fitzgerald et al., 2014; Gilbert et al., 2015). Another recently described species, C. geochelonis, has also been isolated exclusively from reptiles (Gilbert et al., 2014). Despite the high prevalence, C. iguaniorum has never been reported before, whereas the required conditions for isolation are similar to the methods used for species such as C. jejuni. This suggests that reptiles have been overlooked as potential host for Epsilonproteobacteria.

\section{SPECIES DIVERSITY OF REPTILE-ASSOCIATED EPSILONPROTEOBACTERIA}

In total, three Arcobacter species (A. butzleri, A.cryaerophilus, and A. skirrowii), four Campylobacter species (C. fetus, C. geochelonis, C. hyointestinalis, and C. iguaniorum), ten putative novel Helicobacter species, and one putative novel Sulfurospirillum species have been isolated from reptiles (Lawson and Owen, 2007; Stacy and Wellehan, 2010; Gilbert et al., 2014, 2017; Piccirillo et al., 2016). Sulfurospirillum was isolated once from a chelonian and, apart from this isolate, the Sulfurospirillum genus solely consists of members which have been isolated from environmental sources, making it likely that this Sulfurospirillum represents an incidental introduction into a vertebrate host.
The known Epsilonproteobacteria diversity is largely based on studies in humans and production animals, which is only a small fraction of potential hosts. Over the last years more Epsilonproteobacteria species have been described from vertebrate hosts other than humans or companion animals, suggesting a large potential reservoir of undiscovered Epsilonproteobacteria species. This also indicates that the number of validly described Epsilonproteobacteria species is largely limited by the research efforts outside known reservoirs. This is also hampered by the fastidious nature of many vertebrate-associated Epsilonproteobacteria, as the deposit of cultured bacteria in culture collections is mandatory for valid description of a novel species. However, with increasing interest in screening of novel potential reservoirs and especially improved sequencing methods, enabling metagenomics approaches, a large increase in the known Epsilonproteobacteria diversity is expected. With an increase in known diversity, the phylogenetic resolution increases and novel clades might appear.

\section{THERMOTOLERANCE}

Both Campylobacter and Helicobacter include members adapted to either high or low temperatures within the optimum temperature range observed in most birds, mammals, and reptiles. As Campylobacter and Helicobacter form distinct clades, low temperature adaptation has likely evolved independently in both genera. Especially in Helicobacter, this seems to be related to a high level of adaptation to a poikilothermic reptilian host (Gilbert et al., 2017). Low temperature adaptation is prevailing in many other members of the Campylobacteraceae (e.g., freeliving Arcobacter and Sulfurospirillum) and high temperature adaptation might be exceptional. Adaptation to extreme environments is well conserved amongst Epsilonproteobacteria, which have been shown associated with deep-sea thermal vents and hypersaline environments (Donachie et al., 2005; Nakagawa et al., 2005).

No thermotolerant Campylobacter species have been isolated from reptiles (Wang et al., 2013; Gilbert et al., 2014). The Campylobacter species isolated from reptile are all low temperature adapted species from the same clade (C. fetus group). In contrast to other Campylobacter taxa, all share high homology in their NADH:quinone oxidoreductase complex I subunits (NuoA-N) with low temperature adapted Arcobacter (Gilbert et al., 2016a). Indeed, in other organisms NADH:quinone oxidoreductase complex I is considered the most thermolabile protein complex of oxidative phosphorylation (Downs and Heckathorn, 1998). It is tempting to speculate that the high homology observed in the NADH:quinone oxidoreductase complex I subunits reflects parallel evolution which might be related to low temperature adaptation. Amphibians could provide significant insights into bacterial thermal adaptation in poikilothermic hosts. Being non-amniotic vertebrate tetrapods, amphibians are only distantly related to reptiles, although they are often grouped together due to superficial external resemblance and a shared poikilothermic lifestyle. No Epsilonproteobacteria have been reported to be 
isolated from amphibians. Own results based on culturing and PCR indicate that no or few Epsilonproteobacteria are present in amphibians (unpublished data). Parallels exist with Salmonella, a generalist species which is frequently isolated from mammals, birds and reptiles, but not or rarely from amphibians (Briones et al., 2004). This indicates that a poikilothermic nature is not the only predictor in the composition of the poikilothermic vertebrate microbiota and precludes a general thermal adaptation irrespective of host group phylogeny. As for many reptiles, the amphibian diet consists mainly of invertebrates, and although the amphibian intestinal microbiome resembles the amniote microbiome (Kohl et al., 2013), it appears to be less diverse and lacking certain bacterial species typical for reptiles. This suggests that host physiology is important in the microbiome composition and that at least some level of host adaptation occurs, even in generalist species such as Salmonella.

\section{EPSILONPROTEOBACTERIA HOST ASSOCIATION}

The presence of Arcobacter and Campylobacter in a large diversity of reptiles (some taxa have been isolated from lizards, snakes, and chelonians) is indicative of a generalist lifestyle, rather than a specialist lifestyle. Epsilonproteobacteria with a high survival rate outside the vertebrate host, such as some Arcobacter species, tend to show a more relaxed host association than Epsilonproteobacteria with a higher level of host specificity, such as many Helicobacter species. However, by adaptation to a specific niche, the latter can exploit unique resources and might show a competitive advantage and higher survival in its specific niche than generalist species, as can be seen in gastric Helicobacter species (Table 1).

Some Campylobacter species can be found in many different host species, such as $C$. jejuni and $C$. coli. Other species are more associated, or even restricted, to certain hosts such as C. upsaliensis in dogs, C. helveticus in cats, C. insulaenigrae and C. blaseri in seals, and C. fetus subspecies fetus and venerealis in ruminants. C. fetus subsp. testudinum and C. iguaniorum are predominantly isolated from poikilothermic reptiles. At least part of the captive-held reptiles that were screened for Epsilonproteobacteria were living near birds in zoos or were fed on poultry and were most likely exposed to thermotolerant Campylobacter species, such as C. coli and C. jejuni. Nevertheless, despite a generalist lifestyle and broad host range in mammals and birds, combined with suitable culturing methods, these

TABLE 1 | Overview of the Epsilonproteobacteria taxa isolated from reptiles and respective host association.

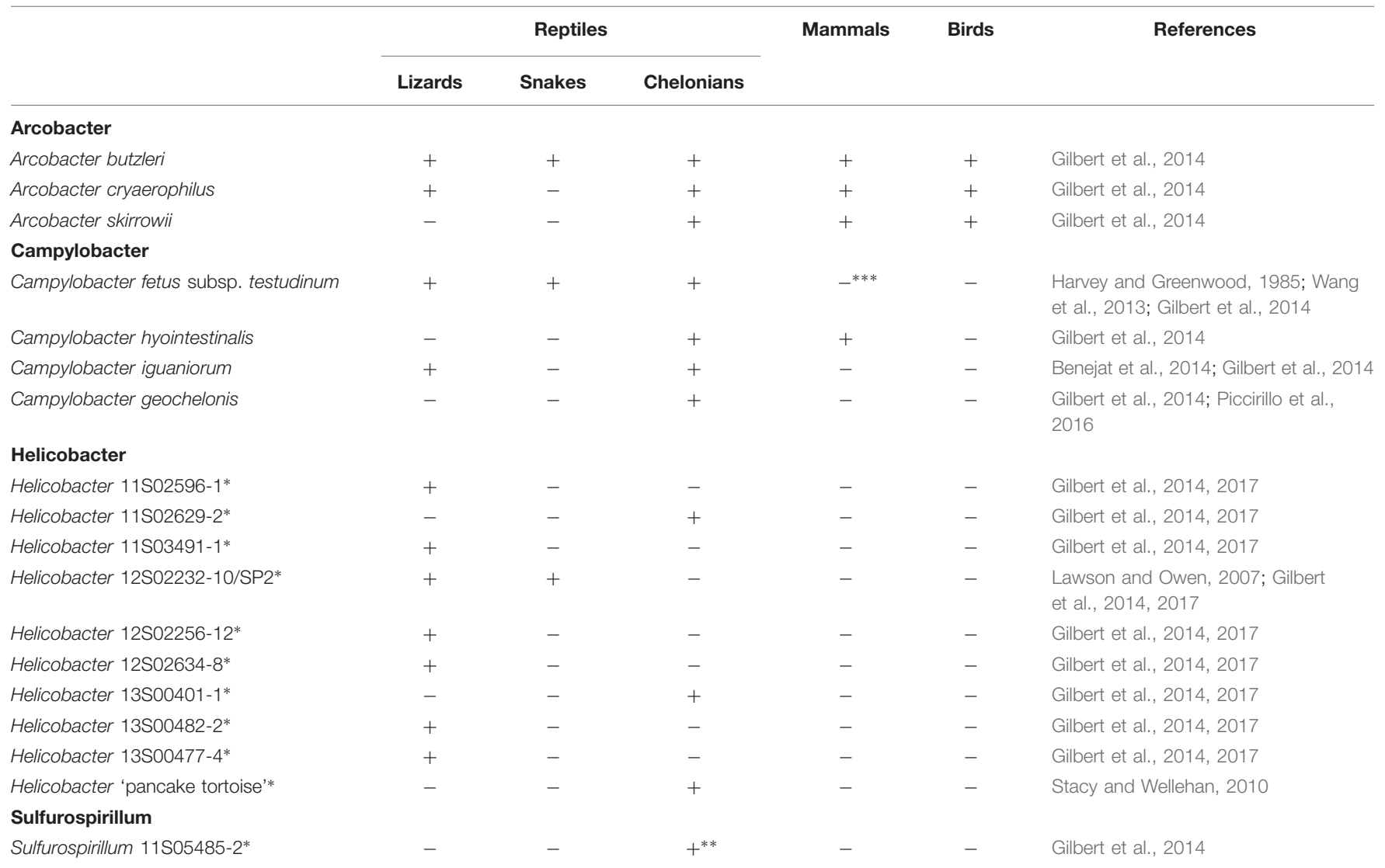

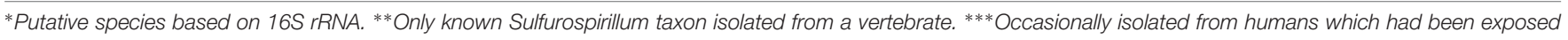
to reptiles in most cases. 
thermotolerant Campylobacter species have not been isolated from reptiles (Gilbert et al., 2014). This shows that, at least for Campylobacter, a distinct host dichotomy is observed at species level. Indeed, comparisons of growth temperature ranges confirmed that most Campylobacter species associated with reptiles can grow at lower temperatures than Campylobacter species associated with mammals and birds (Gilbert et al., 2015). It could be speculated that this is an adaptation to the body temperature encountered in these different hosts. Although the underlying factors for this distinct host association are not entirely clear, genomic studies provide clues about the genetic background of this differential host adaptation, such as the differential homology observed in the NADH:quinone oxidoreductase complex I subunits (Gilbert et al., 2016a,b).

\section{Campylobacter fetus HOST ASSOCIATION}

All highly prevalent Campylobacter species isolated from reptiles (C. fetus, C. hyointestinalis, and C. iguaniorum) are closely related and belong to the same phylogenetic clade. Of this clade, only C. lanienae has not been found in reptiles. Based on the currently known species distribution it is tempting to speculate about a potential reptilian origin of this particular Campylobacter clade. Especially the host preference of $C$. fetus is remarkable. A distinct host dichotomy is encountered within the species: while the subspecies C. fetus subsp. fetus is predominantly isolated from mammals, mostly ruminants, and C. fetus subsp. venerealis is restricted to the reproduction organs of cattle, C. fetus subsp. testudinum is predominantly isolated from reptiles (Table 1). Although, like C. fetus subsp. testudinum, both C. fetus subspecies fetus and venerealis can grow at low temperatures $\left(20-25^{\circ} \mathrm{C}\right)$, these subspecies have never been isolated from reptiles. One of the factors shaping this host dichotomy, as shown by genomic analyses, may be the presence of a tricarballylate catabolism locus in C. fetus subsp. testudinum, which was absent from both mammal-associated C. fetus subspecies (Gilbert et al., 2016b). Interestingly, the tricarballylate catabolism locus was also present in reptile-associated C. iguaniorum and Helicobacter lineages (Gilbert et al., 2016a, 2017). This locus potentially enables C. fetus subsp. testudinum to use the citrate analog tricarballylate as carbon and energy source (Lewis et al., 2004). Tricarballylate is toxic to ruminants by inhibiting aconitase and the citric acid cycle (Russell, 1985). However, reptiles have been shown less susceptible to aconitase inhibition than mammals (McIlroy, 1986). As such, reptiles are expected to be more tolerant to tricarballylate, which might be more abundant in the reptilian intestine than in the mammalian intestine. The uptake of genetic material through lateral gene transfer can give a competitive advantage and the possibility to exploit new niches (Papke and Ward, 2004). In this way, the tricarballylate catabolism locus might have influenced the host adaptation and genetic divergence in C. fetus subsp. testudinum. However, a loss of this locus in mammal-associated C. fetus due to redundancy cannot be excluded. Furthermore, the homology between reptile- and mammal associated $C$. fetus based on average amino acid identity is roughly 95\%, meaning that also other factors influencing host adaptation and genetic divergence in C. fetus might exist and reside in the 5\% average amino acid difference.

Genetic diversity has been shown to be low for C. fetus subspecies fetus and venerealis, and a recent entry from another reservoir into the ruminant host reservoir followed by rapid expansion has been suggested (van Bergen et al., 2005; van der Graaf-van Bloois et al., 2016). Compared to C. fetus subspecies fetus and venerealis, C. fetus subsp. testudinum shows higher genetic diversity (Dingle et al., 2010; Gilbert et al., 2016b), suggesting a more ancient entry of $C$. fetus subsp. testudinum into the reptilian host reservoir and subsequent genetic divergence.

\section{HOST ASSOCIATION OF REPTILE-ASSOCIATED Helicobacter}

Generally, there appears to be an increasing vertebrate host association within the genera Arcobacter, Campylobacter, and Helicobacter, respectively, although some Helicobacter species can occur in multiple hosts as well (Solnick and Schauer, 2001) (Table 1). This host association is nicely illustrated by Helicobacter pylori, which shows an intricate symbiosis with humans, the primary host for this species (Falush et al., 2003). In addition to this, compared to other vertebrate-associated Epsilonproteobacteria genera, the higher number of distinct Helicobacter taxa isolated from many different vertebrate hosts species suggests a higher level of host adaptation and specificity. Also in reptiles the Helicobacter diversity (nine putative species) was higher than Arcobacter and Campylobacter diversity (three species of both genera) (Gilbert et al., 2014, 2017).

In contrast to Arcobacter and Campylobacter, of which most taxa were isolated from all reptilian orders examined, Helicobacter showed stricter host association. Based on 16S rRNA and whole genome phylogeny a Helicobacter clade associated with lizards and a clade associated with chelonians was observed (Gilbert et al., 2014, 2017). These clades were distinct from mammalian and avian Helicobacter species, indicating long-term divergence in a reptilian host. The lizard-associated Helicobacter lineages carried a urease locus and were most closely related to gastric Helicobacter species, while the chelonian-associated Helicobacter species were most closely related to enterohepatic Helicobacter species. This indicated initial adaptation to an anatomical niche and subsequent diversification in either a lizard or chelonian host type. The phylogeny of reptile-associated Helicobacter paralleled association with either a lizard or chelonian host, indicating a high level of host specificity. The high diversity and deep branching within these clades supported long-term coevolution with, and extensive radiation within the respective reptilian host type.

The reptile-associated Helicobacter lineages were able to grow at lower temperatures $\left(25^{\circ} \mathrm{C}\right)$ and a larger temperature range $\left(25-42^{\circ} \mathrm{C}\right)$ than Helicobacter species from birds and mammals, which might reflect thermal adaptation to a reptilian host (Lawson and Owen, 2007; Gilbert et al., 2017). As growth at lower temperatures was observed in both the distantly related chelonian- and in the lizard-associated Helicobacter clade, and 
mammal-associated Helicobacter clades were more basal to these, the ability to grow at lower temperatures likely originated at least twice in Helicobacter evolution.

As in reptile-associated Campylobacter taxa, a tricarballylate catabolism locus was present in all Helicobacter lineages from reptiles, while it was rarely present in Helicobacter species isolated from other host types, indicating that this locus might confer a competitive advantage in a reptilian host. Noteworthy, one of the genes of this locus, tcuC, showed higher homology between Campylobacter fetus subsp. testudinum, C. iguaniorum and the chelonian-associated Helicobacter lineages than the latter and the lizard-associated Helicobacter lineages. This suggests that recombination of the tricarballylate catabolism locus has occurred between Helicobacter and Campylobacter, potentially in a chelonian host.

\section{TRANSMISSION AND SURVIVAL}

Efficient transmission between hosts is crucial for long-term survival of host-adapted bacterial species. Most vertebrateassociated Epsilonproteobacteria rely on a host for long-term survival and show limited viability in the hostile environment outside the host. Indeed, while Campylobacter species can survive in the environment, they are generally not considered to propagate outside of an animal host (Rollins and Colwell, 1986). Some Campylobacter species can persist in moist and aquatic environments, and Campylobacter species can be transmitted via feces contaminated water sources (Baily et al., 2014). Also for Helicobacter species an environmental reservoir is often not known (Solnick and Schauer, 2001). In contrast, vertebrateassociated Arcobacter species can survive in diverse environments and seem to be less dependent on a host for long-term survival (Miller et al., 2007; Ferreira et al., 2016). At least for Campylobacter and Helicobacter, the vertebrate host itself is likely the most important vector.

Transmission can occur from parent to offspring (vertical transmission) or from other sources (horizontal transmission). From a host perspective, transmission is dependent on physiology and contact structures of the host. In mammals, which are viviparous and display intensive parental care, contact structures between parent and offspring are more frequent, enabling efficient vertical transmission of the intestinal microbiota. Although oviparous, most birds show parental care, facilitating vertical transmission of bacteria. In reptiles, which are mostly oviparous and display no or little parental care, vertical transmission is likely less efficient than in mammals and birds. These physiological and behavioral disparities can potentially influence the composition and transmission of the reptilian intestinal microbiota, including the Epsilonproteobacteria. However, several physiological homologies can be found in reptiles and birds, such as oviparous reproduction and having a cloaca, a common distal part of the intestinal, reproductive, and urinary tracts.

The transmission of the intestinal microbiota in reptiles is poorly studied, but relatively well studied for avian intestinal bacterial genera which also occur in reptiles, such as Campylobacter and Salmonella, and parallels to reptiles might exist. Although Campylobacter species are found in the reproductive tracts of poultry, no or little C. jejuni is found in eggs and hatchlings (Camarda et al., 2000; Buhr et al., 2002; Cole et al., 2004). Direct vertical transmission of Campylobacter is considered absent or rare in birds and offspring will become colonized by Campylobacter after birth by fecal-oral transmission (Shanker et al., 1986; Sahin et al., 2002; Callicott et al., 2006). In contrast to Campylobacter, vertical transmission of Salmonella is possible, both by penetrating the egg in the ovaria and by cloacal contamination of the surface during oviposition, and has been shown in poultry (Gantois et al., 2009). A similar mode of infection in reptiles seems plausible. Indeed, penetration of turtle eggs by Salmonella Braenderup has been shown (Feeley and Treger, 1969). Most reptilian eggs are more fibrous and less calciferous compared to the avian egg and are usually highly permeable to water. In most species water uptake by the egg after deposition is crucial in development of the reptilian embryo. For this reason reptile eggs are usually deposited in moist locations. Both the permeable eggshell as the moist incubation could be favorable for vertical transmission of the intestinal microbiota, including the small and often highly motile Epsilonproteobacteria. Furthermore, many lizards and snakes are viviparous or ovoviviparous, giving birth to completely developed young. These factors could promote vertical transmission. Indeed a significant proportion of the intestinal microbiome overlapped between mother and recently born offspring in a live bearing lizard species, suggesting vertical transmission, although environmental transmission could not be excluded (Kohl et al., 2017). As in birds, horizontal transmission is likely important, at least in captivity. Indeed, molecular genotyping indicated that captive, unrelated reptile species having direct or indirect contact can harbor the same specific Epsilonproteobacteria variants (Gilbert et al., 2014). This phenomenon was observed in animals kept in the same housing, animals from the same zoo, and animals originating from the same shipment, indicating that horizontal transmission happens under these conditions. The exact transmission routes remain to be elucidated, but a fecal-oral transmission is likely, especially in captive animals and species displaying coprophagy. Many herbivorous chelonians display coprophagy, presumably to supplement their microbiota needed for hindgut fermentation. Also sexual transmission might play a role. In the common lizard (Zootoca vivipara) it was found that polyandrous females mating with multiple males harbored more diverse cloacal bacterial communities and differed more in community composition than did monandrous females, suggesting that the higher bacterial diversity found in polyandrous females is due to the sexual transmission of bacteria by multiple mates (White et al., 2011).

Regarding spatial transmission, migratory birds are an effective vector for avian-associated Epsilonproteobacteria species. Compared to birds, mammals and especially reptiles show less extensive migration patterns, which are likely influencing the distribution patterns of Epsilonproteobacteria associated with these hosts. This is nicely illustrated in C. jejuni, which occurs in many wild avian hosts and shows a pandemic distribution (Griekspoor et al., 2013). 
To study these factors with little interference, free-living vertebrate populations with as little anthropogenic influences as possible might be favored over captive-held vertebrate populations. Captivity can influence the contact structures, transmission, and observed host association of vertebrateassociated Epsilonproteobacteria. Indeed, Epsilonproteobacteria prevalence has been shown higher in captive-held reptiles, although the number of sampled free-living reptiles was low (Gilbert et al., 2014). Nevertheless, Epsilonproteobacteria have also been identified in recently caught free-living reptiles, indicating the presence of Epsilonproteobacteria in free-living reptiles as well (Gilbert et al., 2014; Kohl et al., 2017; Ahasan et al., 2018). This is in concordance with studies examining Salmonella prevalence in reptiles, which showed a higher prevalence in captive-held reptiles than in free-living reptiles (Richards et al., 2004; Scheelings et al., 2011) and the introduction of Salmonella in captivity (Kohl et al., 2017). Many sampled captive-held reptiles were living in close contact with other animals of the same or other species in a density that is higher than under natural conditions. This may very well lead to other transmission dynamics and an intestinal microbiota composition distinct from free-living animals, as has been shown for mammals (Ochman et al., 2010). Interspecies transmission in unnatural reptile assemblies have been noted before for Campylobacter and Helicobacter (Schrenzel et al., 2010; Gilbert et al., 2014) and indicates that original host association, but also phylogenetic patterns of co-evolution between a vertebrate host and symbiont might be disturbed by anthropogenic influences.

\section{VIRULENCE OF EPSILONPROTEOBACTERIA IN REPTILES}

The presence of Epsilonproteobacteria in many different reptiles without clinical symptoms indicates that most Epsilonproteobacteria taxa are carried without adverse health effects. Herbivorous reptiles (especially tortoises), which rely on their intestinal microbiota for hindgut fermentation and digestion of their vegetarian diet, showed highest Epsilonproteobacteria prevalence and diversity, without apparent adverse health effects. Little is known from literature about Epsilonproteobacteria and disease in reptiles. A Helicobacter species has been reported associated with septicemia in a pancake tortoise (Malacochersus tornieri), in which disseminated infection resulted in regional cellulitis and edema of the head and neck, and pericarditis (Stacy and Wellehan, 2010). However, closely related Helicobacter strains were isolated from tortoises without clinical symptoms, indicating that Helicobacter can be carried without adverse health effects (Gilbert et al., 2014). Furthermore, a Helicobacter species was found associated with septicaemia and mortality in wild blue iguanas (Cyclura lewisi) on Grand Cayman (Popescu, 2018).

C. iguaniorum has been isolated from the feces of a sick leopard tortoise (Stigmochelys pardalis), although this species was isolated from reptiles with and without clinical symptoms (Benejat et al., 2014; Gilbert et al., 2014, 2015). C. fetus subsp. testudinum was the predominantly isolated Epsilonproteobacteria species in snakes and, when present, was isolated in high numbers compared to presence in other reptiles (Gilbert et al., 2014). Noteworthy, all snakes carrying C. fetus subsp. testudinum suffered from often lethal intestinal infections. In humans, C. fetus is known for causing invasive infections with a systemic component (Blaser et al., 2008; Wagenaar et al., 2014), especially in elderly and immunocompromised (Tu et al., 2004; Patrick et al., 2013). If C. fetus subsp. testudinum is associated with infections in snakes, it may very well be that the animals were already weakened due to suboptimal living conditions in captivity, compared to the conditions in the wild, which may lead to malnutrition, stress, high parasite loads, and other disorders, leaving the animals more vulnerable to infection (Girling and Raiti, 2004). Indeed, very few bacteria have been implicated in reptile diseases as primary causative agents (Pasmans et al., 2008), which may be related to a generally more potent innate immune response in reptiles, compared to mammals (Zimmerman et al., 2010).

\section{ZOONOTIC ASPECTS OF REPTILE-ASSOCIATED EPSILONPROTEOBACTERIA}

Most of the Arcobacter and Campylobacter species found in reptiles are associated with disease in humans, although infections are often sporadic and mainly affecting immunocompromised hosts (Lastovica and Allos, 2008; Collado and Figueras, 2011). Currently C. fetus is the only species for which an association between reptile contact and human infection has been demonstrated (Harvey and Greenwood, 1985; Tu et al., 2004; Patrick et al., 2013). Besides from humans, C. fetus subsp. testudinum has only been isolated from reptiles, with a reported culturing-based prevalence of 5.5-6.7\% in reptiles and 7.1-9.7\% in chelonians (Wang et al., 2013; Gilbert et al., 2014). Reptileassociated C. fetus subsp. testudinum showed a remarkable epidemiology, as all human cases were in men, most of whom were of Asian origin (Patrick et al., 2013). All patients with invasive C. fetus subsp. testudinum infections were $>60$ years of age or were immunocompromised. Humans may contract $C$. fetus subsp. testudinum though exposure to reptiles, possibly by ingestion or by contact with feces or the environment. Chelonians are frequently sold in Asian markets for consumption, which could explain the predominance of an Asian origin among reported patients. A GenBank search based on $16 \mathrm{~S}$ rRNA revealed more human infections with C. fetus subsp. testudinum in China. Furthermore, in the period 2012-2013, at least 13 human cases were reported from the Guangzhou area alone (Hou et al., 2015). No epidemiological data were available for these cases, but since chelonians form an integral part of the Chinese cuisine, a reptilian origin is likely for these C. fetus subsp. testudinum infections. Based on multilocus sequence typing (MLST), C. fetus subsp. testudinum strains from human cases in China showed higher genetic diversity compared to those from the United States, and one strain isolated from a human (Hou et al., 2018) showed an identical sequence type (ST17) as a strain isolated from a chelonian (Dingle et al., 2010; Gilbert et al., 2016b), 
further affirming a reptilian origin for C. fetus subsp. testudinum infections in humans.

MLST and genomic data showed that, although geographically separated, all human invasive infections by C. fetus subsp. testudinum in the United States were caused by highly related strains (Dingle et al., 2010; Gilbert et al., 2016b). All invasive C. fetus subsp. testudinum strains uniquely shared a genomic region which was highly homologous in mammal-associated C. fetus and showed signs of recombination (Gilbert et al., 2016b). This region, iamABC (also annotated as mlaFED) is associated with invasion in C. jejuni and might be associated with invasion in these particular C. fetus subsp. testudinum strains as well (Carvalho et al., 2001). Furthermore, the systemic component in C. fetus infection has been shown associated with the surface array layer (S-layer), which protects the bacteria against a complementbased immune response and phagocytosis (Blaser et al., 2008). The S-layer encoding sap locus is highly variable, but can be divided in $s a p A, \operatorname{sap} B$, and occasional $\operatorname{sap} A B$. Both in reptile- as in mammalassociated $C$. fetus sapA type strains are overrepresented in cases of septicemia, which might be related to the serum resistance of sapA type strains, as has been shown for mammal-associated $C$. fetus (Kienesberger et al., 2014). While the genetic diversity of $C$. fetus subsp. testudinum is larger in reptiles (Dingle et al., 2010; Wang et al., 2013; Gilbert et al., 2016b), only certain strains are associated with infection in humans in the United States. Besides genetic factors such as iam $A B C$, this could also be related to differences in exposure to particular C. fetus subsp. testudinum strains. Nevertheless, the predominant occurrence of C. fetus infections in elderly and immunocompromised hosts stresses the importance of the immune system in preventing invasive infection (Blaser et al., 2008).

Of the other Epsilonproteobacteria species isolated from reptiles, A. butzleri, A. cryaerophilus, A. skirrowii, and C. hyointestinalis have all been associated with infections in humans. C. iguaniorum and the Helicobacter taxa have only been isolated from reptiles and have not been associated with infection in humans thus far, except for a case of bacteremia caused by a urease-negative Helicobacter strain, isolated from blood cultures of a 28-year-old man with X-linked agammaglobulinemia (Schwarze-Zander et al., 2010). Based on 16S rRNA homology, this Helicobacter strain was closely related to the Helicobacter clade isolated from chelonians (Stacy and Wellehan, 2010; Gilbert et al., 2014). Noteworthy, the patient had contact with poultry and with snakes, which were fed rodents, and, as this Helicobacter strain is related to the Helicobacter clade isolated from reptiles, the bacteremia caused by this Helicobacter strain might be related to exposure to snakes.

\section{EVOLUTION OF VERTEBRATE-ASSOCIATED EPSILONPROTEOBACTERIA}

The current observed distribution of species is merely a cross section of an evolutionary process which has been going on since the beginning of life, and which is often progressing at speeds undetectable within a human lifespan. As such, each species can be in a different stage of speciation. As pioneered by Woese (1987) based on 16S rRNA, the prokaryotic divisions are ancient, as the evolutionary split of most divisions is predating the origin of animals and often pre-dating the origin of eukaryotes. Also, bacteria hardly fossilize, so in order to reconstruct the bacterial evolutionary trajectory one has to rely on theoretical models based on genetic information. Nevertheless, the evolutionary trajectory for some highly host restricted (endosymbiont) bacterial species can be deduced from the evolutionary trajectory of its host species for which fossils are available, such as for Buchnera and their aphid host (Moran et al., 2008). Co-evolution between a host and its symbiont can be most apparent in case of congruent evolution. In that case both host and symbiont have similar phylogenetic trees. This has been reported for endosymbionts which are highly dependent on one host, are transmitted vertically, and do not have a free-living stage (Papke and Ward, 2004).

Most vertebrate-associated Epsilonproteobacteria are highly dependent on a vertebrate host for survival, and although no endosymbionts, they might show a phylogeny similar to their respective hosts depending on the level of host association. In general, vertebrate host association is highest in Helicobacter, followed by Campylobacter and Arcobacter, although differences between and within species can be observed. This is likely related to a decrease in survival outside the host, e.g., vertebrate-associated Arcobacter species more tolerant to atmospheric oxygen levels than Campylobacter and especially Helicobacter. This in turn might lead to isolation in a particular host and increased speciation, although this is also highly dependent on the host-associated transmission dynamics. This is reflected in the observed Epsilonproteobacteria diversity on species level in both reptiles and vertebrates in total, which is highest for Helicobacter, followed by Campylobacter and Arcobacter.

Indeed, for some vertebrate-associated Epsilonproteobacteria species a congruent evolution has been observed, such as for H. pylori and its human host (Falush et al., 2003; Linz et al., 2007). Considering the rather generalist lifestyle and broad host range of many Campylobacter species, highly similar phylogenies between Campylobacter and their vertebrate hosts are not to be expected. Nevertheless, Campylobacter is vertebrate hostadapted and although able to survive, they are considered unable to propagate outside this host (Rollins and Colwell, 1986). When examining the $16 \mathrm{~S}$ rRNA-based phylogeny of the Campylobacter genus, at least three distinct clades consisting of more than one species can be discerned; C. jejuni and related species, C. fetus and related species, and C. concisus and related species (Figure 1). Interestingly, the C. jejuni clade mainly consists of thermotolerant bird-associated Campylobacter species, the $C$. fetus clade consists of non-thermotolerant reptile- and mammal-associated Campylobacter species, and the $C$. concisus clade solely consists of mammal-associated Campylobacter species. These clades are separated by deep branching in the phylogenetic tree and may even be considered distinct genera (Waite et al., 2017). Although host overlap between birds, mammals, and reptiles is frequent for these three Campylobacter clades, overall Campylobacter phylogeny 
is similar to the overall phylogeny of these vertebrate groups. One could speculate that these different Campylobacter clades are associated and co-evolving with these vertebrate groups since the last common ancestor of these amniotic vertebrate hosts diverged. However, there are also indications that the large-scale evolutionary pattern of Campylobacter and Helicobacter can be explained by initial adaptation to a particular (anatomical) niche and subsequent divergence in different vertebrate host types. For example, the C. concisus clade predominantly consists of oral Campylobacter species, while reptile-associated Helicobacter lineages do not form one separate clade distinct from mammal and bird-associated Helicobacter species, but instead form two separate clades, which are most closely related to, but distinct from, either enterohepatic or gastric Helicobacter species associated with mammals and birds (Gilbert et al., 2014, 2017).

For the vertebrate-associated Epsilonproteobacteria most evolutionary studies have focused on the human pathogens $H$. pylori and C. jejuni. Due to its high host specificity and efficient vertical transmission over a prolonged time, $H$. pylori and humans co-evolved and $H$. pylori phylogeny reflects human phylogeny (Falush et al., 2003; Linz et al., 2007). At least in some cases, gastric disease can be explained by disruption of the co-evolved human and H. pylori lineages (Kodaman et al., 2014). Although considered a human pathogen, $H$. pylori can be beneficial to its human host as well (Atherton and Blaser, 2009), illustrating an intricate long-term symbiosis. Nevertheless, no Helicobacter species closely related to human $H$. pylori were isolated from chimpanzees, our closest extant relatives, suggesting that the association between $H$. pylori and humans is of more recent times than the divergence time between both species (Moodley et al., 2012). This could be explained by host jumps between distantly related vertebrates, as $H$. pylori was most closely related to $H$. acinonychis from large felines (Eppinger et al., 2006). In contrast, C. jejuni shows a broad vertebrate host range. Birds are considered to be the primary host, which carry the bacteria without obvious clinical symptoms. C. jejuni has efficiently entered the agricultural niche and colonizes both avian and mammalian livestock. Mostly from this reservoir C. jejuni can colonize humans and cause infection. C. jejuni and the closely related C. coli both occur in the same agricultural niche and extensive genetic recombination and introgression between these two separate species has been shown (Sheppard et al., 2008). In C. jejuni, the frequency of recombination may be higher in genes which experience higher selection pressure, such as surface exposed structure encoding genes (Caro-Quintero et al., 2009), but recombination also occurs in conserved and essential housekeeping genes, which are expected to experience less selection pressure (Sheppard et al., 2008). The same dataset has been used to model the timescale of evolution for C. jejuni, C. coli, C. fetus, and several related Campylobacter species based on MLST (Wilson et al., 2009). This study indicated that speciation within the included Campylobacter species occurred on a timescale of thousands of years and it was speculated that the C. jejuni-C. coli split coincided with the Neolithic domestication of a wide variety of animal species around 10,000 years ago. This was in contrast to conventional estimates, which indicated a timescale of millions of years for Campylobacter evolution (Wilson et al., 2009).

\section{EVOLUTION OF Campylobacter fetus}

Some studies have focused on the evolution of C. fetus ( $\mathrm{Tu}$ et al., 2005; Kienesberger et al., 2014; Gilbert et al., 2016b; van der Graaf-van Bloois et al., 2016). This species consists of two genetically divergent and coherent lineages, each with a distinct host association, either mammal- or reptile-associated. While the subspecies C. fetus subsp. fetus is predominantly isolated from mammals, mostly ruminants, and C. fetus subsp. venerealis is restricted to cattle, C. fetus subsp. testudinum is predominantly isolated from reptiles. It was questioned whether this distinct host dichotomy was the result of divergence and subsequent co-evolution of mammal-and reptile-associated C. fetus with their respective mammalian and reptilian hosts since their last shared ancestor or whether this host-association was the result of a more recent host crossing event.

The large genetic diversity of reptile-associated C. fetus subsp. testudinum in reptiles indicates that the reptilian host is likely a more ancient reservoir for $C$. fetus than the mammalian host. The large genetic divergence between mammal and reptile-associated C. fetus suggests that this is not a recent host-crossing event and reptile-associated $C$. fetus subsp. testudinum is not the direct ancestor of mammal-associated C. fetus (Gilbert et al., 2016b). Furthermore, the isolation of C. fetus ST43 and ST69, another divergent $C$. fetus lineage which is more related to mammalthan to reptile-associated C. fetus from chelonians, indicates that C. fetus diversity is larger than foreseen (Wang et al., 2013; Gilbert et al., 2014, 2018). Based on 16S rRNA and whole genome sequence-based homology, these strains and mammal-associated C. fetus have a more recent common ancestor. Based on current knowledge, C. fetus diversity is larger in reptiles, which may be the primary C. fetus reservoir from which mammal-associated C. fetus originated. The finding of additional divergent $C$. fetus strains can provide further insights in C. fetus evolution, but also stresses that evolutionary insights can be largely influenced by screening efforts. Large-scale screening of wild mammals and reptiles is needed to fill in the gaps in C. fetus evolution.

While allopatric speciation is considered the most common form of speciation in organisms that tend not to disperse over large distances, this is often inferred to be a rare event in the evolution of bacteria (Papke and Ward, 2004). This is largely based on the assumptions that bacteria are small, have large population sizes, and have the ability to survive hostile environments in a resistant physiologically inactive stage during transport. However, while many of these assumptions apply to free-living bacteria, this only partly applies to C. fetus and other Epsilonproteobacteria adapted to vertebrate host with a low dispersal capacity. Furthermore, vertebrateassociated Epsilonproteobacteria do not form endospores and are highly sensitive to desiccation. Nevertheless, some Epsilonproteobacteria, like mammal-associated C. fetus, have shown to be genetically uniform across the globe (van Bergen et al., 2005). In this case, anthropogenic influences have likely blurred the original distribution patterns, as mammal-associated C. fetus has been transported together with their ruminant host across the globe as livestock (van der Graaf-van Bloois et al., 2016). One would expect 
some level of geographical isolation, reflected in the C. fetus genome. However, host association of Campylobacter genotypes has been shown to transcend geographic variation for C. fetus and C. jejuni (van Bergen et al., 2005; Sheppard et al., 2010; Griekspoor et al., 2013). This indicates that, at least for these species, host type is more important than geographic location in explaining genotypic variation. For example, on different continents similar MLST sequence types are observed for C. fetus and C. jejuni in cattle and poultry, respectively (van Bergen et al., 2005; Sheppard et al., 2010). Another interesting finding is that blackbirds from Europe and Australia (where they have been introduced) harbored similar sequence types (Griekspoor et al., 2013).

C. fetus, and C. fetus subsp. venerealis in particular, has a very high level of niche adaptation. This niche may be so narrow that many genetic adaptations will be detrimental and disadvantageous for niche persistence, confining the number of genetic variants. Nevertheless, it has to be noted that $16 \mathrm{~S}$ rRNA and the MLST housekeeping genes are highly conserved and no or little genetic variants are observed in mammalassociated C.fetus. This indicates that mammal-associated C.fetus is coherent and expanded recently in the agricultural niche, allowing little time for diversification (Gilbert et al., 2016b; van der Graaf-van Bloois et al., 2016). Compared to other C. fetus variants, C. fetus subsp. venerealis displays the largest accessory genome due to the acquisition of non-homologous genetic material. This might be related to a less effective defense against foreign DNA, such as the absence of a complete CRISPR/Cas system (Gilbert et al., 2016b). Parts of the accessory genome are thought to be specific for $C$. fetus subsp. venerealis and might confer the cattle restricted niche specificity (Kienesberger et al., 2014). Gene acquisition by lateral gene transfer might have enabled C. fetus subsp. venerealis to exploit a slightly different niche. By adaptation to this niche, $C$. fetus subsp. venerealis could escape the force of cohesion with C. fetus subsp. fetus and start diverging by accumulation of point mutations. The force of cohesion is likely a combination of homologous recombination and purging of less adapted genetic variants. Indeed, this divergence has been observed in the core genomes of $C$. fetus subspecies fetus and venerealis (van der Graaf-van Bloois et al., 2014). The adaptation to different and often cryptic ecological niches has been demonstrated for C. jejuni, in which the two major generalist lineages did not show evidence of recombination with each other in nature, despite having a high degree of host niche overlap and recombining extensively with specialist lineages (Sheppard et al., 2014). However, transformation experiments showed that the generalist lineages readily recombine with one another in vitro. This suggested ecological rather than essential barriers to recombination, caused by a cryptic niche structure within the hosts. The large genetic distance observed between mammal- and reptile-associated C. fetus indicates prolonged divergence of both lineages (Gilbert et al., 2016b). The rarity of recent homologous recombination observed between mammaland reptile-associated C. fetus supports effective isolation of both lineages and indicates that there are barriers to genetic exchange. Such barriers can be divided into three categories: mechanistic, ecological, and adaptive (Sheppard et al., 2008). As these C. fetus lineages inhabit either mammals or reptiles, an ecological barrier, resulting from the occupation of distinct niches, is likely most important. This is supported by the observation that C. fetus ST69, a lineage highly related to mammal-associated C. fetus subsp. fetus, yet isolated from chelonians, shows high recombination rates with reptile-associated $C$. fetus subsp. testudinum when occurring in a shared chelonian host (Gilbert et al., 2018). In contrast, gene flow between C. fetus and C. iguaniorum, which are both occurring in the same reptilian host, was rare, suggesting effective barriers to recombination despite having a similar niche (Gilbert et al., 2018). Depending on the frequency of homologous recombination, bacteria can range from either clonally to sexually reproducing organisms (Fraser et al., 2007). Within C. fetus, mutation through homologous recombination has been shown more important than mutation through point mutation in reptileassociated C. fetus subsp. testudinum, compared to mammalassociated C. fetus subspecies fetus and venerealis (Gilbert et al., 2016b). Also, recombination has likely disrupted the association between genome phylogeny and sap type in reptile- but not in mammal-associated C. fetus, as both sap types can be present in some clades in C. fetus subsp. testudinum, while only one sap type is present in each clade in C. fetus subspecies fetus and venerealis. As such, C. fetus subsp. testudinum can be considered to reproduce more sexually, whether $C$. fetus subspecies fetus and venerealis show more clonal reproduction. In stable and rather static environments a clonal reproduction mode can be favorable, whereas in unstable and dynamic environments a sexual reproduction mode can be more favorable for survival, providing the variation needed for selection to act upon (MacLean et al., 2013). For C. fetus, this can be explained from an ecological perspective, as mammal-associated C. fetus currently appears to be primarily restricted to a rather narrow host niche in an agricultural setting, whereas reptile-associated C. fetus shows a broad host niche amongst various reptile lineages, as diverse as squamates (lizards and snakes), chelonians, and crocodilians (Gilbert et al., 2014). The large genetic diversity observed in C. fetus subsp. testudinum supports an ancient introduction in the reptilian host, although intrinsic factors generating this genetic diversity cannot be excluded. Although both mammals and reptiles are likely occasionally exposed to both mammal- and reptile-associated C. fetus, and both lineages show the same growth temperature range, the distinct host dichotomy maintains, suggesting effective host adaptation of either lineage.

Unlike in most Campylobacter species, a proteinaceous S-layer is present in $C$. fetus, encoded by sap genes, which can be $\operatorname{sap} A, \operatorname{sap} B$, or occasionally $\operatorname{sap} A B$. These sap variants correlate with the lipopolysaccharide composition, which can either be serotype $A$ or $B$, with serotype $A B$ being a minor variant of serotype B (Blaser et al., 2008). As most reptile-associated $C$. fetus were type $A$, it was suggested that this was the ancestral type, after which type B diverged in mammals ( $\mathrm{Tu}$ et al., 2005; Kienesberger et al., 2014). However, the subsequent discovery of type B strains in reptileassociated $C$. fetus suggests that both types originated before reptile- and mammal-associated C. fetus diverged (Gilbert et al., 2016b). It remains to be shown how both types have 
remained conserved over time in both divergent reptile- and mammal-associated C. fetus lineages.

Although co-evolution of mammal and reptile-associated C. fetus with their respective mammalian and reptilian hosts since their last common ancestor has been suggested (Tu et al., 2001), this has been refuted by others based on evolutionary rate modeling (Wilson et al., 2009), and, based on current knowledge and species distribution, a more recent crossing event from a reptilian, or from another, unknown host, to a mammalian host seems more plausible. Indeed, considering the ancient split of mammals and reptiles, 320-315 million years ago (Mya), and the massive radiation and diversification of species afterward, effective co-evolution between Campylobacter and their hosts would be reflected in a higher diversity in C. fetus, much more genetic divergence between mammal- and reptileassociated C. fetus, and to another phylogenetic composition of the Campylobacter genus as a whole, especially considering the short generation time and high mutation rate normally encountered in bacteria. A stable intestinal environment could provide protection and promote genetic stability over time. However, physiology of the mammalian and reptilian intestinal tract has evolved in separate ways as well. This diversity of distinct intestinal niches is not reflected in the currently observed Campylobacter diversity.

There is little theoretical support for the timescale hypothesized by $\mathrm{Tu}$ et al. (2005). However, there are large differences in the evolutionary timescales, depending on the molecular clock model considered. Based on Campylobacter MLST data, the split between C. fetus and C. jejuni was calculated to have occurred $33.8 \mathrm{Kya}$, whereas this split occurred 51.4 Mya according to the most relaxed model (Wilson et al., 2009). Based on whole genome sequence data, it has been shown that diversification of mammal-associated C. fetus is a relatively recent event, as the split of the most basal clades was predicted to have occurred 10.5 Kya to more than 40 Kya (van der Graafvan Bloois et al., 2016; Iraola et al., 2017). When compared to related vertebrate-associated Epsilonproteobacteria species, the model proposed by Wilson et al. (2009) might be too strict and the timescale proposed for Campylobacter evolution too narrow. For example, $H$. pylori has been co-evolving with

\section{REFERENCES}

Ahasan, M. S., Waltzek, T. B., Huerlimann, R., and Ariel, E. (2018). Comparative analysis of gut bacterial communities of green turtles (Chelonia mydas) pre-hospitalization and post-rehabilitation by high-throughput sequencing of bacterial 16S rRNA gene. Microbiol. Res. 207, 91-99. doi: 10.1016/j.micres.2017.11.010

Atherton, J. C., and Blaser, M. J. (2009). Coadaptation of Helicobacter pylori and humans: ancient history, modern implications. J. Clin. Invest. 119, 2475-2487. doi: 10.1172/JCI38605

Baily, J. L., Méric, G., Bayliss, S., Foster, G., Moss, S. E., and Watson, E. (2014). Evidence of land-sea transfer of the zoonotic pathogen Campylobacter to a wildlife marine sentinel species. Mol. Ecol. 24, 208-221. doi: 10.1111/mec. 13001

Benejat, L., Gravet, A., Sifré, E., Ben Amor, S., Quintard, B., Mégraud, F., et al. (2014). Characterization of a Campylobacter fetus-like strain isolated from the faeces of a sick leopard tortoise (Stigmochelys pardalis) using matrixassisted laser desorption/ionization time of flight as an alternative to bacterial humans and diversity reflects human ancestry and migration patterns out of Africa an estimated 50-70 Kya (Moodley et al., 2012). This indicates that $H$. pylori diversified extensively during this timescale, but diversity has not crossed the species boundaries. According to the molecular clock proposed by Wilson et al. (2009), Campylobacter evolved into at least 13 separate species within a similar timescale. Although Campylobacter and Helicobacter might show intrinsic differences which influence the speciation rate, such large differences are not to be expected.

In all likeliness, a reliable bacterial molecular clock for longer evolutionary timescales is not realistic without calibration based on ancestral reference points. Processes like lateral gene transfer can potentially change the evolutionary trajectory of all bacteria with only a single gene transfer event. Due to ancestral interspecies lateral gene transfer, the evolutionary trajectory of each gene can potentially be different from the evolutionary trajectory of the bacteria in which the gene resides at a particular time. In that way a molecular clock would rather predict the evolutionary timescale of a gene or genome than of the organism itself.

\section{EPILOGUE}

Reptiles harbor an unexpectedly high Epsilonproteobacteria diversity and many of these taxa are uniquely associated with reptiles. Especially Helicobacter shows extensive host adaptation and diversification within the reptilian host. Despite the advances made, many questions remain largely unanswered, such as the Epsilonproteobacteria prevalence and transmission in wild reptiles, pathogenicity of Epsilonproteobacteria in reptiles, the factors determining host adaptation, and the timescale of Epsilonproteobacteria evolution. Future studies are needed to address these questions in further depth.

\section{AUTHOR CONTRIBUTIONS}

MG wrote the manuscript. $\mathrm{BD}, \mathrm{AZ}$, and JW reviewed the manuscript.

16S rDNA phylogeny. Lett. Appl. Microbiol. 58, 338-343. doi: 10.1111/lam. 12194

Blaser, M. J., Newell, D. G., Thompson, S. A., and Zechner, E. L. (2008). "Pathogenesis of Campylobacter fetus," in Campylobacter, eds I. Nachamkin, C. M. Szymanski, and M. J. Blaser (Washington, DC: ASM Press), 401-428.

Briones, V., Téllez, S., Goyache, J., Ballesteros, C., del Pilar Lanzarot, M., Domínguez, L., et al. (2004). Salmonella diversity associated with wild reptiles and amphibians in Spain. Environ. Microbiol. 6, 868-871.

Buhr, R. J., Cox, N. A., Stern, N. J., Musgrove, M. T., Wilson, J. L., and Hiett, K. L. (2002). Recovery of Campylobacter from segments of the reproductive tract of broiler breeder hens. Avian Dis. 46, 919-924.

Callicott, K. A., Friethriksdottir, V., Reiersen, J., Lowman, R., Bisaillon, J. R., and Gunnarsson, E. (2006). Lack of evidence for vertical transmission of Campylobacter spp. in chickens. Appl. Environ. Microbiol. 72, 5794-5798.

Camarda, A., Newell, D. G., Nasti, R., and Di Modugnoa, G. (2000). Genotyping Campylobacter jejuni strains isolated from the gut and oviduct of laying hens. Avian Dis. 44, 907-912. 
Caro-Quintero, A., Rodriguez-Castano, G. P., and Konstantinidis, K. T. (2009). Genomic insights into the convergence and pathogenicity factors of Campylobacter jejuni and Campylobacter coli species. J. Bacteriol. 191, 5824-5831. doi: 10.1128/JB.00519-09

Carvalho, A. C., Ruiz-Palacios, G. M., Ramos-Cervantes, P., Cervantes, L. E., Jiang, X., and Pickering, L. K. (2001). Molecular characterization of invasive and noninvasive Campylobacter jejuni and Campylobacter coli isolates. J. Clin. Microbiol. 39, 1353-1359.

Cole, K., Donoghue, A. M., Blore, P. J., and Donoghue, D. J. (2004). Isolation and prevalence of Campylobacter in the reproductive tracts and semen of commercial turkeys. Avian Dis. 48, 625-630.

Collado, L., and Figueras, M. J. (2011). Taxonomy, epidemiology, and clinical relevance of the genus Arcobacter. Clin. Microbiol. Rev. 24, 174-192. doi: 10.1128/CMR.00034-10

Costello, E. K., Gordon, J. I., Secor, S. M., and Knight, R. (2010). Postprandial remodeling of the gut microbiota in Burmese pythons. ISME J. 4, 1375-1385. doi: 10.1038/ismej.2010.71

Debruyne, L., Gevers, D., and Vandamme, P. (2008). "Taxonomy of the family Campylobacteraceae," in Campylobacter, eds I. Nachamkin, C. M. Szymanski, and M. J. Blaser (Washington, DC: ASM Press), 3-25.

Dingle, K. E., Blaser, M. J., Tu, Z. C., Pruckler, J., Fitzgerald, C., van Bergen, M. A., et al. (2010). Genetic relationships among reptilian and mammalian Campylobacter fetus strains determined by multilocus sequence typing. J. Clin. Microbiol. 48, 977-980. doi: 10.1128/JCM.01439-09

Donachie, S. P., Bowman, J. P., On, S. L., and Alam, M. (2005). Arcobacter halophilus sp. nov., the first obligate halophile in the genus Arcobacter. Int. J. Syst. Evol. Microbiol. 55, 1271-1277.

Downs, C. A., and Heckathorn, S. A. (1998). The mitochondrial small heat-shock protein protects NADH: ubiquinone oxidoreductase of the electron transport chain during heat stress in plants. FEBS Lett. 430, 246-250.

Eppinger, M., Baar, C., Linz, B., Raddatz, G., Lanz, C., and Keller, H. (2006). Who ate whom? Adaptive Helicobacter genomic changes that accompanied a host jump from early humans to large felines. PLoS Genet. 2:e120. doi: 10.1371/journal.pgen.0020120.eor

Falush, D., Wirth, T., Linz, B., Pritchard, J. K., Stephens, M., Kidd, M., et al. (2003). Traces of human migrations in Helicobacter pylori populations. Science 299, 1582-1585.

Feeley, J. C., and Treger, M. D. (1969). Penetration of turtle eggs by Salmonella braenderup. Public Health Rep. 84, 156-158.

Ferreira, S., Queiroz, J. A., Oleastro, M., and Domingues, F. C. (2016). Insights in the pathogenesis and resistance of Arcobacter: a review. Crit. Rev. Microbiol. 42, 364-383. doi: 10.3109/1040841X.2014.954523

Fitzgerald, C., Tu, Z. C., Patrick, M., Stiles, T., Lawson, A. J., and Santovenia, M. (2014). Campylobacter fetus subsp. testudinum subsp. nov., isolated from humans and reptiles. Int. J. Syst. Evol. Microbiol. 64, 2944-2948. doi: 10.1099/ ijs.0.057778-0

Fraser, C., Hanage, W. P., and Spratt, B. G. (2007). Recombination and the nature of bacterial speciation. Science 315, 476-480.

Gantois, I., Ducatelle, R., Pasmans, F., Haesebrouck, F., Gast, R., Humphrey, T. J., et al. (2009). Mechanisms of egg contamination by Salmonella Enteritidis. FEMS Microbiol. Rev. 33, 718-738. doi: 10.1111/j.1574-6976.2008.00161.x

Gilbert, M. J., Duim, B., Timmerman, A. J., Zomer, A. L., and Wagenaar, J. A. (2017). Whole genome-based phylogeny of reptile-associated Helicobacter indicates independent niche adaptation followed by diversification in a poikilothermic host. Sci. Rep. 7:8387. doi: 10.1038/s41598-017-09091-7

Gilbert, M. J., Duim, B., van der Graaf-van Bloois, L., Wagenaar, J. A., and Zomer, A. L. (2018). Homologous recombination between genetically divergent Campylobacter fetus lineages supports host-associated speciation. Genome Biol. Evol. 10, 716-722. doi: 10.1093/gbe/evy048

Gilbert, M. J., Kik, M., Miller, W. G., Duim, B., and Wagenaar, J. A. (2015). Campylobacter iguaniorum sp. nov., isolated from reptiles. Int. J. Syst. Evol. Microbiol. 65, 975-982. doi: 10.1099/ijs.0.000048

Gilbert, M. J., Kik, M., Timmerman, A. J., Severs, T. T., Kusters, J. G., Duim, B., et al. (2014). Occurrence, diversity, and host association of intestinal Campylobacter, Arcobacter, and Helicobacter in reptiles. PLoS One 9:e101599. doi: 10.1371/journal.pone.0101599

Gilbert, M. J., Miller, W. G., Yee, E., Kik, M., Zomer, A. L., Wagenaar, J. A., et al. (2016a). Comparative genomics of Campylobacter iguaniorum to unravel genetic regions associated with reptilian hosts. Genome Biol. Evol. 8, 30223029 .

Gilbert, M. J., Miller, W. G., Yee, E., Zomer, A. L., van der Graaf-van Bloois, L., and Fitzgerald, C. (2016b). Comparative genomics of Campylobacter fetus from reptiles and mammals reveals divergent evolution in host-associated lineages. Genome Biol. Evol. 8, 2006-2019. doi: 10.1093/gbe/evw146

Girling, S., and Raiti, P. (2004). BSAVA Manual of Reptiles, 2nd Edn. Quedgeley: British Small Animal Veterinary Association.

Goodwin, C. S., Armstrong, J. A., Chilvers, T., Peters, M., Collins, M. D., Sly, L., et al. (1989). Transfer of Campylobacter pylori and Campylobacter mustelae to Helicobacter gen. nov. as Helicobacter pylori comb. nov. and Helicobacter mustelae comb. nov., respectively. Int. J. Syst. Bacteriol. 39, 397-405.

Griekspoor, P., Colles, F. M., McCarthy, N. D., Hansbro, P. M., Ashhurst-Smith, C., Olsen, B., et al. (2013). Marked host specificity and lack of phylogeographic population structure of Campylobacter jejuni in wild birds. Mol. Ecol. 22, 1463-1472. doi: 10.1111/mec.12144

Harvey, S., and Greenwood, J. R. (1985). Isolation of Campylobacter fetus from a pet turtle. J. Clin. Microbiol. 21, 260-261.

Hermans, D., Pasmans, F., Heyndrickx, M., Van Immerseel, F., Martel, A., Van Deun, K., et al. (2012). A tolerogenic mucosal immune response leads to persistent Campylobacter jejuni colonization in the chicken gut. Crit. Rev. Microbiol. 38, 17-29. doi: 10.3109/1040841X.2011.615298

Hong, P., Wheeler, E., Cann, I. K., and Mackie, R. I. (2011). Phylogenetic analysis of the fecal microbial community in herbivorous land and marine iguanas of the Galápagos Islands using 16S rRNA-based pyrosequencing. ISME J. 5, 1461-1470.

Hou, S., Qu, P., Wu, Y., Zhang, X., Hu, Y., Deng, Z., et al. (2015). The identification and multilocus sequence typing of nine Campylobacter fetus isolates from specimens of patients from 2012 to 2013. Zhonghua Yu Fang Yi Xue Za Zhi 49, 744-746.

Hou, S. P., He, P., Zhou, Y., and Wu, X. W. (2018). Complete genome sequence of Campylobacter fetus subsp. testudinum strain 772, isolated from ascites of a patient with chronic kidney disease. Genome Announc. 6:e00432-18. doi: 10.1128/genomeA.00432-18

Iraola, G., Forster, S. C., Kumar, N., Lehours, P., Bekal, S., and García-Peña, F. J. (2017). Distinct Campylobacter fetus lineages adapted as livestock pathogens and human pathobionts in the intestinal microbiota. Nat. Commun. 8:1367. doi: 10.1038/s41467-017-01449-9

Keenan, S. W., Engel, A. S., and Elsey, R. M. (2013). The alligator gut microbiome and implications for archosaur symbioses. Sci. Rep. 3:2877. doi: 10.1038/ srep02877

Kienesberger, S., Sprenger, H., Wolfgruber, S., Halwachs, B., Thallinger, G. G., and Perez-Perez, G. I. (2014). Comparative genome analysis of Campylobacter fetus subspecies revealed horizontally acquired genetic elements important for virulence and niche specificity. PLoS One 9:e85491. doi: 10.1371/journal.pone. 0085491

Kodaman, N., Pazos, A., Schneider, B. G., Piazuelo, M. B., Mera, R., and Sobota, R. S. (2014). Human and Helicobacter pylori coevolution shapes the risk of gastric disease. Proc. Natl. Acad. Sci. U.S.A. 111, 1455-1460. doi: 10.1073/pnas. 1318093111

Kohl, K. D., Brun, A., Magallanes, M., Brinkerhoff, J., Laspiur, A., and Acosta, J. C. (2017). Gut microbial ecology of lizards: insights into diversity in the wild, effects of captivity, variation across gut regions and transmission. Mol. Ecol. 26, 1175-1189. doi: 10.1111/mec. 13921

Kohl, K. D., Cary, T. L., Karasov, W. H., and Dearing, M. D. (2013). Restructuring of the amphibian gut microbiota through metamorphosis. Environ. Microbiol. Rep. 5, 899-903. doi: 10.1111/1758-2229.12092

Lastovica, A. J., and Allos, B. M. (2008). "Clinical significance of Campylobacter and related species other than Campylobacter jejuni and Campylobacter coli," in Campylobacter, eds I. Nachamkin, C. M. Szymanski, and M. J. Blaser (Washington, DC: ASM Press), 123-149.

Lawson, A., and Owen, R. (2007). Helicobacter serpensis, a Novel Helicobacter species Isolated from Snake Faeces. (Zoonoses and Public Health Ser, Vol. 54. Oxford: Blackwell Publishing, 73-73.

Lewis, J. A., Horswill, A. R., Schwem, B. E., and Escalante-Semerena, J. C. (2004). The tricarballylate utilization $(t c u R A B C)$ genes of Salmonella enterica serovar Typhimurium LT2. J. Bacteriol. 186, 1629-1637. 
Ley, R. E., Hamady, M., Lozupone, C., Turnbaugh, P. J., Ramey, R. R., and Bircher, J. S. (2008). Evolution of mammals and their gut microbes. Science 320, 1647-1651. doi: 10.1126/science. 1155725

Lin, D., and Koskella, B. (2015). Friend and foe: factors influencing the movement of the bacterium Helicobacter pylori along the parasitismmutualism continuum. Evol. Appl. 8, 9-22. doi: 10.1111/eva.12231

Linz, B., Balloux, F., Moodley, Y., Manica, A., Liu, H., and Roumagnac, P. (2007). An African origin for the intimate association between humans and Helicobacter pylori. Nature 445, 915-918. doi: 10.1038/nature05562

MacLean, R. C., Torres-Barceló, C., and Moxon, R. (2013). Evaluating evolutionary models of stress-induced mutagenesis in bacteria. Nat. Rev. Genet. 14, 221-227. doi: $10.1038 / \operatorname{nrg} 3415$

McIlroy, J. (1986). The sensitivity of Australian animals to 1080 poison. 9. Comparisons between the major groups of animals, and the potential danger nontarget species face from 1080 poisoning campaigns. Wildl. Res. 13, 39-48.

Miller, W. G., Parker, C. T., Rubenfield, M., Mendz, G. L., Wösten, M. M., and Ussery, D. W. (2007). The complete genome sequence and analysis of the epsilonproteobacterium Arcobacter butzleri. PLoS One 2:e1358. doi: 10.1371/ journal.pone.0001358

Moodley, Y., Linz, B., Bond, R. P., Nieuwoudt, M., Soodyall, H., and Schlebusch, C. M. (2012). Age of the association between Helicobacter pylori and man. PLoS Pathog. 8:e1002693. doi: 10.1371/journal.ppat.1002693

Moran, N. A., McCutcheon, J. P., and Nakabachi, A. (2008). Genomics and evolution of heritable bacterial symbionts. Annu. Rev. Genet. 42, 165-190. doi: 10.1146/annurev.genet.41.110306.130119

Nakagawa, S., Takai, K., Inagaki, F., Hirayama, H., Nunoura, T., Horikoshi, K., et al. (2005). Distribution, phylogenetic diversity and physiological characteristics of epsilon-Proteobacteria in a deep-sea hydrothermal field. Environ. Microbiol. 7, 1619-1632.

Ochman, H., Worobey, M., Kuo, C. H., Ndjango, J. B., Peeters, M., Hahn, B. H., et al. (2010). Evolutionary relationships of wild hominids recapitulated by gut microbial communities. PLoS Biol. 8:e1000546. doi: 10.1371/journal.pbio. 1000546

Olson, C. K., Ethelberg, S., van Pelt, W., and Tauxe, R. V. (2008). "Epidemiology of Campylobacter jejuni infections in industrialized nations," in Campylobacter, eds I. Nachamkin, C. M. Szymanski, and M. J. Blaser (Washington, DC: ASM Press), 163-189.

On, S. L., Holmes, B., and Sackin, M. J. (1996). A probability matrix for the identification of campylobacters, Helicobacters and allied taxa. J. Appl. Bacteriol. 81, 425-432.

Papke, R. T., and Ward, D. M. (2004). The importance of physical isolation to microbial diversification. FEMS Microbiol. Ecol. 48, 293-303. doi: 10.1016/j. femsec.2004.03.013

Parsonnet, J., Friedman, G. D., Vandersteen, D. P., Chang, Y., Vogelman, J. H., Orentreich, N., et al. (1991). Helicobacter pylori infection and the risk of gastric carcinoma. N. Engl. J. Med. 325, 1127-1131.

Pasmans, F., Blahak, S., Martel, A., and Pantchev, N. (2008). Introducing reptiles into a captive collection: the role of the veterinarian. Vet. J. 175, 53-68.

Patrick, M. E., Gilbert, M. J., Blaser, M. J., Tauxe, R. V., Wagenaar, J. A., and Fitzgerald, C. (2013). Human infections with new subspecies of Campylobacter fetus. Emerg. Infect. Dis. 19, 1678-1680. doi: 10.3201/eid1910.130883

Piccirillo, A., Niero, G., Calleros, L., Pérez, R., Naya, H., and Iraola, G. (2016). Campylobacter geochelonis sp. nov. isolated from the western Hermann's tortoise (Testudo hermanni hermanni). Int. J. Syst. Evol. Microbiol. 66, 3468-3476. doi: 10.1099/ijsem.0.001219

Popescu, I. S. (2018). Investigations into Green Iguana (Iguana iguana) as a Potential Carrier for a Novel Strain of Helicobacter spp, Pathogenic for the Endangered Blue Iguana (Cyclura lewisi). Master's thesis, University of Edinburgh. doi: 10.13140/RG.2.2.27240.93441

Ren, T., Kahrl, A. F., Wu, M., and Cox, R. M. (2016). Does adaptive radiation of a host lineage promote ecological diversity of its bacterial communities? A test using gut microbiota of Anolis lizards. Mol. Ecol. 25, 4793-4804. doi: $10.1111 / \mathrm{mec} .13796$

Richards, J. M., Brown, J. D., Kelly, T. R., Fountain, A. L., and Sleeman, J. M. (2004). Absence of detectable Salmonella cloacal shedding in free-living reptiles on admission to the wildlife center of Virginia. J. Zoo Wildl. Med. 35, 562-563.
Rollins, D. M., and Colwell, R. R. (1986). Viable but nonculturable stage of Campylobacter jejuni and its role in survival in the natural aquatic environment. Appl. Environ. Microbiol. 52, 531-538.

Russell, J. B. (1985). Enrichment and isolation of rumen bacteria that reduce trans-aconitic acid to tricarballylic acid. Appl. Environ. Microbiol. 49, $120-126$.

Sahin, O., Morishita, T. Y., and Zhang, Q. (2002). Campylobacter colonization in poultry: sources of infection and modes of transmission. Anim. Health Res. Rev. 3, 95-105.

Scheelings, T. F., Lightfoot, D., and Holz, P. (2011). Prevalence of Salmonella in Australian reptiles. J. Wildl. Dis. 47, 1-11.

Schrenzel, M. D., Witte, C. L., Bahl, J., Tucker, T. A., Fabian, N., and Greger, H. (2010). Genetic characterization and epidemiology of Helicobacters in nondomestic animals. Helicobacter 15, 126-142. doi: 10.1111/j.1523-5378.2009. 00744.x

Schwarze-Zander, C., Becker, S., Wenzel, J., Rockstroh, J. K., Spengler, U., and Yassin, A. F. (2010). Bacteremia caused by a novel Helicobacter species in a 28-year-old man with X-linked agammaglobulinemia. J. Clin. Microbiol. 48, 4672-4676. doi: 10.1128/JCM.01350-10

Shanker, S., Lee, A., and Sorrell, T. C. (1986). Campylobacter jejuni in broilers: the role of vertical transmission. J. Hyg. 96, 153-159.

Sheppard, S. K., Cheng, L., Méric, G., Tucker, T. A., Fabian, N., and Greger, H. (2014). Cryptic ecology among host generalist Campylobacter jejuni in domestic animals. Mol. Ecol. 23, 2442-2451. doi: 10.1111/mec.12742

Sheppard, S. K., Colles, F., Richardson, J., Cody, A. J., Elson, R., and Lawson, A. (2010). Host association of Campylobacter genotypes transcends geographic variation. Appl. Environ. Microbiol. 76, 5269-5277. doi: 10.1128/AEM. 00124-10

Sheppard, S. K., McCarthy, N. D., Falush, D., and Maiden, M. C. (2008). Convergence of Campylobacter species: implications for bacterial evolution. Science 320, 237-239. doi: 10.1126/science.115 5532

Smith, T., and Taylor, M. S. (1919). Some morphological and biological characters of the spirilla (Vibrio fetus, n. sp.) associated with disease of the fetal membranes in cattle. J. Exp. Med. 30, 299-311.

Solnick, J. V., and Schauer, D. B. (2001). Emergence of diverse Helicobacter species in the pathogenesis of gastric and enterohepatic diseases. Clin. Microbiol. Rev. 14, 59-97.

Stacy, B. A., and Wellehan, J. F. Jr. (2010). Fatal septicemia caused by Helicobacter infection in a pancake tortoise (Malacochersus tornieri). J. Vet. Diagn. Invest. 22, 660-662.

Tu, Z. C., Dewhirst, F. E., and Blaser, M. J. (2001). Evidence that the Campylobacter fetus sap locus is an ancient genomic constituent with origins before mammals and reptiles diverged. Infect. Immun. 69, 2237-2244.

Tu, Z. C., Eisner, W., Kreiswirth, B. N., and Blaser, M. J. (2005). Genetic divergence of Campylobacter fetus strains of mammal and reptile origins. J. Clin. Microbiol. 43, 3334-3340.

Tu, Z. C., Zeitlin, G., Gagner, J. P., Keo, T., Hanna, B. A., and Blaser, M. J. (2004). Campylobacter fetus of reptile origin as a human pathogen. J. Clin. Microbiol. 42, 4405-4407.

van Bergen, M. A., Dingle, K. E., Maiden, M. C., Newell, D. G., van der GraafVan Bloois, L., van Putten, J. P., et al. (2005). Clonal nature of Campylobacter fetus as defined by multilocus sequence typing. J. Clin. Microbiol. 43, 5888-5898.

van der Graaf-van Bloois, L., Duim, B., Miller, W. G., Forbes, K. J., Wagenaar, J. A., and Zomer, A. (2016). Whole genome sequence analysis indicates recent diversification of mammal-associated Campylobacter fetus and implicates a genetic factor associated with H2S production. BMC Genomics 17:713. doi: 10.1186/s12864-016-3058-7

van der Graaf-van Bloois, L., Miller, W. G., Yee, E., Rijnsburger, M., Wagenaar, J. A., and Duim, B. (2014). Inconsistency of phenotypic and genomic characteristics of Campylobacter fetus subspecies requires re-evaluation of current diagnostics. J. Clin. Microbiol. 52, 4183-4188.

Vandamme, P., Falsen, E., Rossau, R., Hoste, B., Segers, P., Tytgat, R., et al. (1991). Revision of Campylobacter, Helicobacter, and Wolinella taxonomy: emendation of generic descriptions and proposal of Arcobacter gen. nov. Int. J. Syst. Bacteriol. 41, 88-103. 
Voogdt, C. G., Bouwman, L. I., Kik, M. J., Wagenaar, J. A., and Van Putten, J. P. (2016). Reptile Toll-like receptor 5 unveils adaptive evolution of bacterial flagellin recognition. Sci. Rep. 6:19046. doi: 10.1038/srep 19046

Wagenaar, J. A., van Bergen, M. A., Blaser, M. J., Tauxe, R. V., Newell, D. G., and van Putten, J. P. (2014). Campylobacter fetus infections in humans: exposure and disease. Clin. Infect. Dis. 58, 1579-1586. doi: 10.1093/cid/ ciu085

Waite, D. W., Vanwonterghem, I., Rinke, C., Parks, D. H., Zhang, Y., Takai, K., et al. (2017). Comparative genomic analysis of the class Epsilonproteobacteria and proposed reclassification to Epsilonbacteraeota (phyl. nov.). Front. Microbiol. 8:682. doi: $10.3389 /$ fmicb.2017.00682

Wang, C. M., Shia, W. Y., Jhou, Y. J., and Shyu, C. L. (2013). Occurrence and molecular characterization of reptilian Campylobacter fetus strains isolated in Taiwan. Vet. Microbiol. 164, 67-76. doi: 10.1016/j.vetmic.2013. 01.008

White, J., Richard, M., Massot, M., and Meylan, S. (2011). Cloacal bacterial diversity increases with multiple mates: evidence of sexual transmission in female common lizards. PLoS One 6:e22339. doi: 10.1371/journal.pone. 0022339
Wilson, D. J., Gabriel, E., Leatherbarrow, A. J., Cheesbrough, J., Gee, S., and Bolton, E. (2009). Rapid evolution and the importance of recombination to the gastroenteric pathogen Campylobacter jejuni. Mol. Biol. Evol. 26, 385-397. doi: $10.1093 / \mathrm{molbev} / \mathrm{msn} 264$

Woese, C. R. (1987). Bacterial evolution. Microbiol. Rev. 51, 221-271.

Zimmerman, L. M., Vogel, L. A., and Bowden, R. M. (2010). Understanding the vertebrate immune system: insights from the reptilian perspective. J. Exp. Biol. 213, 661-671. doi: 10.1242/jeb.038315

Conflict of Interest Statement: The authors declare that the research was conducted in the absence of any commercial or financial relationships that could be construed as a potential conflict of interest.

Copyright (c) 2019 Gilbert, Duim, Zomer and Wagenaar. This is an open-access article distributed under the terms of the Creative Commons Attribution License (CC BY). The use, distribution or reproduction in other forums is permitted, provided the original author(s) and the copyright owner(s) are credited and that the original publication in this journal is cited, in accordance with accepted academic practice. No use, distribution or reproduction is permitted which does not comply with these terms. 